\title{
MANAJEMEN SEKOLAH BERBASIS 5 PILAR: ISLAMIC, GREEN, LEADERSHIP, CHILDREN FRIENDLY, DAN INCLUSIVE UNTUK MENGEMBANGKAN AKHLAK ISLAMI PESERTA DIDIK
}

\author{
Chafid Sugianto $^{a)}$, Griet Helena Laihad ${ }^{b)}$, Sutji Harijanto ${ }^{b^{*}}$ \\ ${ }^{a)}$ SMA Negeri Kabupaten Bogor, Bogor, Indonesia \\ ${ }^{b)}$ Universitas Pakuan, Bogor, Indonesia \\ *e-mail korespondensi: sutjihar@unpak.ac.id
}

riwayat artikel : diterima: 19 Februari 2020; direvisi: 27 Maret 2020; disetujui: 29 April 2020

\begin{abstract}
Abstrak. Penelitian ini bertujuan untuk untuk memperoleh gambaran berdasarkan fakta berupa data dan informasi mengenai manajemen Sekolah Dasar Kreativa berbasis 5 pilar: Islamic, Green, Leadership, Children Friendly, dan Inclusive dalam rangka mengembangkan akhlak Islami peserta didik. Penelitian ini menggunakan metode kualitatif, dengan peneliti sebagai instrumen. Teknik pengambilan data yang digunakan dengan wawancara, observasi, dan studi dokumentasi. Berdasarkan data dan informasi yang ada, dapat disimpulkan bahwa fungsi manajemen dari perencanaan, pengorganisasian, pengarahan, dan pengendalian berperan penting dalam mencapai tujuan sekolah. Manajemen sekolah berupaya untuk mencapai tujuan pengembangan akhlak Islami siswa melalui penerapan 5 pilar: Islamic, Green, Leadership, Children Friendly, dan Inclusive sebagai dasar program pendidikan di SD Kreativa. Untuk mencapai tujuan dimaksud dibutuhkan perencanaan yang memiliki konsep yang kuat untuk mencapai tujuan, pengorganisasian yang disesuaikan dengan kebutuhan sekolah, pengarahan sumber daya sesuai dengan program yang telah direncanakan dan diorganisasikan, serta pengendalian yang mencakup semua komponen program pendidikan.
\end{abstract}

Kata Kunci: manajemen sekolah; akhlak Islami; lima pilar

\section{PILAR BASED SCHOOL MANAGEMENT: ISLAMIC, GREEN, LEADERSHIP, CHILDREN FRIENDLY, AND INCLUSIVE TO DEVELOP ISLAMIC MORALS OF STUDENTS}

\begin{abstract}
This study is intended to obtain the picture of the 5 pillars of the Kreativa Elementary School management: Islamic, Green, Leadership, Children Friendly, and Inclusive in the form of data and information in order to develop Islamic morals of the students. This research uses qualitative methods, with the researcher as an instrument. The data collection techniques used were interviews, observation, and documentation study. Based on the existing data and information, it can be concluded that the management function of planning, organizing, directing, and controlling plays an important role in achieving the school goals. School management strives to achieve the goal of developing Islamic morals for students through the application of 5 pillars: Islamic, Green, Leadership, Children Friendly, and Inclusive as the basis for educational programs at Kreativa Elementary School. To achieve these goals, it requires planning that has a strong concept to achieve goals, organizing that is tailored to the needs of the school, directing resources according to the program that has been planned and organized, and control that includes all components of the educational program.
\end{abstract}

Keywords: school management; Islamic morals; 5 pillars.

\section{PENDAHULUAN}

Sekolah Dasar Kreativa memberikan konsep sekolah yang mengajarkan nilai-nilai agama Islam, peduli dengan lingkungan, membentuk perilaku kepemimpinan dan ramah anak dengan memberikan kenyamanan peserta didik saat belajar, selain itu guru juga memfasilitasi minat yang dimiliki oleh semua jenis peserta didik, termasuk anak berkebutuhan khusus dapat mengenyam pendidikan secara bersama-sama dengan siswa reguler sebagai program inklusi. Sekolah Dasar Kreativa menerapkan dasar 5 pilar: Islamic, Green, Leadership, Children Friendly, dan Inclusive untuk mengakomodir pencapaian tujuan sekolah. Penerapan 5 pilar sebagai filosofi sekolah berupaya untuk memecahkan masalah-masalah masa kini, namun juga berimbas positif terhadap prestasi siswa dan sekolah. Prestasi yang telah diperoleh siswa maupun Sekolah Dasar Kreativa dan keunikan dalam penerapan dasar sekolah menjadikan daya tarik untuk mendalami bagaimana manajemen Sekolah Dasar Kreativa berbasis 5 pilar: Islamic, Green, Leadership, Children Friendly, dan Inclusive dalam rangka mengembangkan akhlak Islami peserta didik.

Manajemen merupakan ilmu dalam perencanaan, pengorganisasian, pengarahan, pemotivasian, dan pengendalian terhadap sumber daya manusia dan mekanisme kerja untuk mencapai tujuan (Siswanto, 2011:78). Proses dalam manajemen sebuah organisasi terdiri dari perencanaan yang direncanakan dalam tahap awal kemudian diatur penugasannya dan diarahkan dalam pelaksanaannya. Pemberian motivasi juga dilakukan untuk membuat sumber daya semakin terpacu untuk mencapai 
tujuan organisasi melalui program yang dilaksanakan. Tahap akhir yaitu pengendalian untuk memberikan umpan balik terhadap proses yang telah dilaksanakan dalam organisasi supaya tidak menyimpang dari tujuan organisasi. Manajemen juga merupakan suatu seni pengelolaan organisasi. Proses manajemen ini berlangsung secara kontinu yang di dalamnya tidak hanya bermuatan kemampuan melainkan juga didukung dengan pemanfaatan keterampilan sumber daya manusia dalam bentuk tenaga dan pikiran yang secara khusus dimanfaatkan untuk dapat melakukan pekerjaan secara efektif dan efisien melalui perencanaan yang matang, pengorganisasian, dan pengawasan sehingga diperoleh hasil yang optimal. Hal tersebut juga selaras dengan pernyataan R. Terry (dalam Arif dan Zulkarnain, 2008: 236-247) yang menyatakan bahwa manajemen merupakan suatu proses yang terdiri dari tindakan perencanaan, pengorganisasian, penggerakan dan pengendalian yang dilakukan untuk menentukan serta mencapai tujuan yang telah ditentukan melalui pemanfaatan sumber daya manusia dan sumber daya lainnya. Berdasarkan penjabaran tersebut, dapat ditarik sintesis bahwa manajemen merupakan suatu ilmu untuk mengatur organisasi dengan memanfaatkan seluruh sumber daya organisasi yang ada secara efektif dan efisien untuk mencapai tujuan yang ingin dicapai. Organisasi harus dikelola oleh pengelola yang memiliki kemampuan yang kompeten sehingga dapat mencapai tujuan yang diharapkan organisasi melalui pemanfaatan sumber daya yang efektif dan efisien.

Manajemen yang dibahasa dalam penelitian ini terkait manajemen sekolah berbasis 5 pilar: Islamic, Green. Leadership, Children Friendly, dan Inclusive dalam rangka mengembangkan akhlak Islami peserta didik. Islamic dapat diartikan upaya sadar manusia untuk mencerminkan prinsip-prinsip dan cita-cita Islam yang ditafsirkan secara relatif terbatas (Hasan, 2016). Manusia yang beragama Islam menerapkan prinsip-prinsip agama Islam dalam kehidupan sehari-harinya. Islamic yaitu usaha meyakini bahwa Tuhan itu ada dan memberikan wahyunya untuk membimbing umat-Nya yang diterapkan melalui perilaku kehidupan sehari-hari sesuai dengan prinsip ajaran agama Islam. Cabral (2019:887-900) menyatakan "Green attitude has been referred as the feelings which includes evaluative action to engage in environmental performance". Perilaku penghijauan ini direferensikan dengan aksi untuk menjaga lingkungan, supaya manusia tetap menjaga alam dengan baik. Green bisa diartikan sikap yang didasarkan kesadaran dan kepedulian untuk menghargai lingkungan alam sekitar. Prinsip kepemimpinan berfokus membantu para siswa untuk bertanggung jawab atas kehidupan mereka, bekerja dengan orang lain secara efektif, dan melakukan hal yang benar meskipun tak seorangpun memperhatikan (Covey, 2008:43-52). Leadership atau kepemimpinan dapat diartikan nilai atau sikap seseorang untuk mempengaruhi diri sendiri dan orang lain untuk mencapai tujuan yang ditetapkan dan bertanggung jawab atas keputusan yang dibuatnya. Penerapan konsep pendidikan ramah anak memiliki tujuan untuk membentuk anak yang berkarakter positif (akhlaqul karimah) dengan pendekatan kasih sayang dan berbasis humanistik. Ketika pendidikan menerapkan konsep ramah anak maka akan terjadi pembentukan karakter positif peserta didik. Children friendly atau ramah anak khususnya di sekolah yaitu sebuah tindakan untuk memberikan kenyamanan kepada anak dalam belajar dan memberikan kesempatan untuk mengembangkan minat siswa. Pendidikan inklusi erat kaitanya dengan anak berkebutuhan khusus, namun Robinson (2017:164-178) menyatakan proses yang terdapat dalam sistem pendidikan yang memberikan kesempatan dan partisipasi yang sama serta menghargai perbedaan dan keadilan sosial dalam belajar baik itu individu normal ataupun yang memiliki kebutuhan khusus. Inclusive atau pendidikan inklusi dapat disintesiskan yaitu suatu sistem yang menempatkan anak normal dan anak berkebutuhan khusus dalam satu kelas untuk memberikan persamaan kesempatan dalam belajar. Mahmud (2019:29-40) menjelaskan secara lebih sederhana, akhlak Islami yatu sebagai akhlak yang berdasarkan ajaran Islam atau Akhlak yang bersifat Islami. Akhlak Islami adalah sifat yang tertanam dalam jiwa dan mempengaruhi tingkah laku manusia yang didasari ajaran agama Islam

\section{METODE PENELITIAN}

Metode penelitian yang digunakan adalah metode kualitatif deskriptif yang bertujuan untuk mendeskripsikan, menjabarkan, dan melakukan analisis kritis secara objektif berdasarkan pada data dan informasi nyata yang ada dan terjadi di lapangan mengenai manajemen sekolah berbasis 5 pilar: Islamic, Green. Leadership, Children Friendly, dan Inclusive dalam rangka mengembangkan akhlak Islami peserta didik. Penelitian dilaksanakan di Sekolah Dasar Kreativa-Bogor yang menerapkan 5 pilar: Islamic, Green. Leadership, Children Friendly, dan Inclusive sebagai dasar program pendidikannya.

Penelitian ini mengandalkan peneliti sebagai instrumen utama. Pengumpulan data dan informasi menggunakan kajian mendalam melalui proses wawancara, observasi, dan studi dokumentasi mengenai gejala, masalah, serta fakta atau realita yang ada pada objek penelitian. Selanjutnya dilakukan proses eksplorasi pemahaman dengan cara mengumpulkan informasi sebanyak mungkin dari informan didukung dengan data observasi dan dokumentasi untuk kemudian dianalisis dan dideskripsikan, sehingga diperoleh interpretasi mendalam

\section{HASIL DAN PEMBAHASAN}

Temuan hasil penelitian berdasarkan analisis antar situs terhadap empat sub fokus penelitian yang diperoleh melalui wawancara, observasi, dan studi dokumentasi kepada delapan informan di Sekolah Dasar Kreativa dijabarkan sebagai berikut: 


\section{a. Sub Fokus 1: Perencanaan}

Berdasarkan hasil pengendalian dan tujuan yang ingin dicapai, SD Kreativa menyusun rencana program pendidikan ditetapkan sejak awal tahun dengan memperhatikan hasil evaluasi tahun sebelumnya dan melalui hasil diskusi dan masukan dari Yayasan serta Komite Sekolah. Hal tersebut sejalan dengan pendapat Afifudin (dalam Sutikno, 2012 89) menjelaskan bahwa perencanaan merupakan keseluruhan proses pemikiran secara matang terhadap hal yang akan dikerjakan untuk mencapai tujuan yang telah ditentukan.

Perencanaan peserta didik biasa dan berkebutuhan khusus sebagai input Sekolah Dasar Kreativa untuk prioritas pertama mengandalkan lulusan dari TK Kreativa, dan yang kedua berasal dari luar yakni TK disekitarnya yang masih dalam radius satu Kelurahan Tanah Sareal, Kota Bogor. Sekolah menetapkan tema dan konsep pembelajaran kepada peserta didik. Tema dan konsep Pendidikan di Sekolah Dasar Kreativa sesuai dengan dasar 5 pilar sekolah:

a. Sekolah mengajarkan nilai agama Islam sesuai dengan pilar Islamic.

b. Sekolah menumbuhkan kepedulian terhadap lingkungan sesuai dengan pilar Green.

c. Sekolah menanamkan jiwa kepemimpinan peserta didik sesuai dengan pilar Leadership.

d. Sekolah ramah anak, menggali potensi siswa, dan memberikan materi pembelajaran sesuai dengan perkembangan usia anak sesuai dengan pilar Children Friendly.

e. Sekolah memberikan kesempatan kepada anak berkebutuhan khusus belajar bersama dengan anak biasa lainnya. Selain itu, sekolah menanamkan nilai saling menghargai hak anak untuk memperoleh pendidikan, menghormati kawannya, dan peduli sesama manusia meskipun berbeda, sesuai dengan pilar Inclusive

Sasaran dan tujuan pendidikan yang diterapkan di Sekolah Dasar Kreativa tertuang dalam visi sekolah untuk mewujudkan sekolah berprestasi berbasis lingkungan yang ramah anak dan mengedepankan pencapaian akhlak Islami serta nilai kepemimpinan setiap siswa. Melalui dasar 5 pilar: Islamic, Green, Leadership, Children Friendly, dan Inclusive sebagai panduan untuk menggali potensi dan mengembangkan akhlak Islami peserta didik.

Perencanaan program pendidikan didasarkan dari 5 pilar: Islamic, Green, Leadership, Children Friendly, dan Inclusive diintegrasikan dengan kurikulum 2013. Penyusunan program pendidikan juga memperhatikan evaluasi yang dilaksanakan sekolah. Kurikulum untuk peserta didik berkebutuhan khusus menggunakan kurikulum 2013 yang di modifikasi dengan kebutuhan peserta didik. Sekolah menyusun konsep pendidikan yang kemudian dituangkan dalam program tahunan, program semester/silabus, dan program mingguan/ RPP. Program tahunan disusun oleh manajemen sekolah disahkan dalam rapat kerja yayasan, kemudian disosialisasikan dan dibagi penugasannya dalam rapat kerja sekolah. Selanjutnya, fasilitator berkoordinasi dengan kepala sekolah dan wakil kepala sekolah menyusun program semester/silabus dan program mingguan/RPP

\section{b. Sub Fokus 2: Pengorganisasian}

Pada tahap pengorganisasian, pembagian tugas sudah dilaksanakan melalui pembagian struktur organisasi sekolah yang disesuaikan dengan kebutuhan. Sumber daya manusia SD Kreativa melakukan pengelolaan dan pemanfaatan sumber daya lainnya untuk pelaksanaan kegiatan pembelajaran. Hal tersebut sejalan dengan pendapat Nurochim (2016:150-151) yang menyatakan bahwa pengorganisasian merupakan proses kegiatan penyusunan struktur organisasi yang disesuaikan dengan tujuan, sumber, dan lingkungan untuk memilih orang yang tepat serta menempatkan dukungan sarana dan prasarana untuk mencapai tujuan yang telah ditentukan.

SD Kreativa merupakan sekolah yang didirikan oleh Yayasan Apirasi Muslimah Indonesia (Yasmina) sehingga sebagian pengelolaan sekolah dibantu oleh manajemen yayasan. Struktur organisasi Sekolah Kreativa terdiri dari manajemen yayasan yang menurunkan wewenangnya kepada manajemen SD Kreativa. Manajemen Yayasan Yasmina dipimpin oleh Direktur Yayasan terdiri dari Manajemen SDM dan Umum, Manajemen Penjamin Mutu, Manajemen Humas, Manajemen Keuangan Sekolah, Manajemen Koperasi dan 3 Unit Manajemen Sekolah Jenjang Pendidikan yaitu TK, SD, dan SMP Kreativa. Manajemen SD Kreativa dipimpin oleh Kepala Sekolah Dasar dibantu oleh 4 Wakil Kepala Sekolah yaitu Wakil Kepala Sekolah Tingkat Tinggi, Wakil Kepala Sekolah Tingkat Rendah, Wakil Kepala Sekolah Bidang Al Quran, dan Koordinator PPABK (Program Pembelajaran Anak Berkebutuhan Khusus). Struktur organisasi disusun berdasarkan pembagian tugas dan fungsi disesuaikan dengan kebutuhan sekolah. Struktur organisasi SD Kreativa cenderung tetap, namun pengisian jabatannya fleksibel atau bisa terjadi rotasi pengisian jabatan. Pengisi jabatan di manajemen sekolah akan didiskusikan oleh Manajemen Yayasan dan Kepala Sekolah. Selanjutnya, penugasan jabatan disahkan melalui Surat Keputusan (SK) yang dikeluarkan oleh yayasan.

Sumber daya pengelolaan pendidikan di SD Kreativa antara lain sumber daya manusia, sumber daya sarana dan prasarana, sumber daya teknologi, dan sumber daya keuangan. Sumber daya manusia sebagai sumber daya utama yang bertugas mengelola sumber daya lainnya di sekolah. Kualitas SDM pengelola sekolah sangat diperhatikan mulai dari rekrutmen hingga evaluasi. Peningkatan kompetensi selalu dilakukan kepada sumber daya manusia agar dapat selaras dengan perkembangan jaman. Sumber daya sarana prasarana sebagai sumber daya pendukung proses pendidikan di sekolah. Sarana prasarana dikelola supaya membuat peserta didik nyaman untuk belajar. Sumber daya teknologi untuk memberikan kemudahan baik akademis maupun administrasi pembelajaran. Penggunaan teknologi untuk mempermudah pengelolaan sumber daya yang ada di sekolah 
secara efektif dan efisien. Sumber daya keuangan sebagai dukungan administratif sumber daya lainnya. Dukungan keuangan SD Kreativa berasal dari Bantuan Operasional Sekolah (BOS) dan iuran orang tua peserta didik.

Kriteria calon peserta didik untuk mendaftar di SD Kreativa sesuai dengan ketentuan Kementerian Pendidikan dan Kebudayaan. Calon peserta didik minimal berusia 6 tahun. SD Kreativa membuka kesempatan bagi siswa regular dan siswa berkebutuhan khusus untuk belajar bersama di sekolah melalui program pendidikan inklusi. Calon peserta didik SD Kreativa diwawancara dan diobservasi oleh psikolog dan fasilitator. Observasi dilakukan untuk melihat kematangan peserta didik seperti memahami pembicaraan dan kemampuan adaptasi di sekolah. Selanjutnya dilakukan wawancara kepada orang tua dan calon peserta didik sekaligus diberikan penjelasan mengenai program pendidikan di SD Kreativa. Calon peserta didik berkebutuhan khusus akan melalui tahapan yaitu screening awal dan tes psikologi. Screening awal dilakukan oleh Koordinator PPABK melalui wawancara dan observasi awal untuk melihat kebutuhan khusus peserta didik. Selanjutnya, terdapat tes psikolog yang melihat lebih detail kategori kebutuhan khusus calon peserta didik, termasuk dalam kategori ringan, sedang, atau berat. Psikolog memberikan catatan untuk sekolah dalam mendampingi calon peserta didik berkebutuhan khusus. Pada tahun ajaran 2019/2020, sekolah memberikan pembelajaran kepada 14 anak berkebutuhan khusus yang terdiri dari 13 anak memiliki kelainan autis dan 1 anak memiliki kelainan tunarungu.

Kriteria pendidik SD Kreativa secara umum ialah beragama Islam, menyukai dunia anak, dan pendidikan sesuai dengan jabatan yang dibutuhkan. Kriteria pendidik di SD Kreativa djabarkan sebagai berikut:

a. Berusia maksimal 35 tahun

b. Beragama Islam

c. Perempuan menggunakan busana muslimah, laki-laki tidak merokok

d. Memiliki kemampuan dan passion dalam mengajar

e. Mencintai anak-anak

f. Pembelajar cepat, kreatif, disiplin, dan inovatif

g. Berorientasi kerja tim

h. Memiliki loyalitas baik

i. Berdomisili di Bogor dan bersedia melakukan rangkaian seleksi di Bogor

Calon pendidik SD Kreativa diharuskan melewati beberapa rangkaian tes antara lain seleksi administrasi, tes tertulis, tes membaca Al-Quran, tes microteaching, dan tes wawancara oleh kepala sekolah dan bagian SDM yayasan. Kriteria bagian manajemen diharuskan memiliki pengalaman minimal 5 tahun dan menunjukan dedikasi, loyalitas, serta visi yang sama terhadap lembaga. Kriteria yang ditetapkan sekolah untuk menjaga kualitas SDM pengelola pendidikan di SD Kreativa.

Metode pengelompokan kegiatan di SD Kreativa dalam penerapan 5 pilar dibagi menjadi 2 kegiatan, yaitu kegiatan pembelajaran di kelas dan kegiatan pembiasaan. Materi pembelajaran diintegrasikan dengan dasar 5 pilar sekolah: Islamic, Green, Leadership, Children Friendly, dan Inclusive. Tema pembelajaran yang ada pada kurikulum kemudian di integrasikan dengan nilai yang ada pada dasar 5 pilar. Kegiatan pembiasaan penerapan 5 pilar di lakukan melalui:

a. Rekayasa sekolah

Sekolah menciptakan lingkungan yang mengingatkan peserta didik untuk selalu menerapkan nilai 5 pilar sekolah. contohnya seperti: penataan display kata-kata motivasi.

b. Teladan dari SDM pengelola Pendidikan

Fasilitator dan jajaran manajemen sekolah memberikan teladan penerapan 5 pilar kepada peserta didik. Contohnya seperti: penggunaan bahasa positif dan melihatkan kebiasaan pemimpin.

c. Kebijakan

Peraturan yang ditetapkan oleh sekolah untuk dilaksanakan oleh seluruh SDM yang berada di sekolah. contohnya seperti: kebijakan zero plastic zone dan pelibatan siswa dalam student led conference.

d. Kegiatan yayasan dan sekolah

Penguatan dilakukan melalui kegiatan yang diselenggarakan oleh yayasan dan sekolah terkait dengan dasar 5 pilar. contohnya leadership day, market day, peringatan hari ozon, dan peringatan hari besar lainnya.

\section{c. Sub Fokus 3: Pengarahan}

Pada tahap pengarahan, Sekolah memiliki tujuan untuk membuat sekolah berprestasi yang mengembangkan pencapaian akhlak Islami peserta didik. Fasilitator ditugaskan untuk membantu mencapai tujuan tersebut. Pimpinan memberikan pengarahan dan motivasi kepada fasilitator untuk tetap di jalur yang sesuai dalam mencapai tujuan sekolah. Hal tersebut sejalan dengan pendapat Arabiun (2014: 25-44) menyatakan bahwa pengarahan adalah menggerakan sumber daya organisasi untuk bekerja secara efisien untuk mencapai tujuan organisasi.

Pendelegasian wewenang dalam pengarahan dimulai dari direktur yayasan yang mendelegasikan wewenangnya kepada seluruh manajemen pendukung termasuk manajemen sekolah. Kepala SD Kreativa mendelegasikan wewenangnya kepada wakil 
kepala sekolah dan fasilitator baik secara langsung ataupun berjenjang. Proses pengarahan dilakukan secara rutin dan berjenjang. Direktur yayasan setiap bulan memberikan pengarahan dan pemberian motivasi terhadap manajemen sekolah. Kepala sekolah akan meneruskan pengarahan yang diberikan direktur yayasan kepada wakil kepala sekolah dan fasilitator secara rutin setiap bulan melalui kegiatan briefing akbar. Kepala sekolah juga melakukan pengarahan kepada wakil kepala sekolah dan diteruskan kepada fasilitator setiap minggunya terkait program pembelajaran siswa.

Penerapan pengelolaan pendidikan dilaksanakan sesuai dengan perencanaan dan pembagian tugas yang sudah ditetapkan. Pelaksanaan program pendidikan dijalankan sesuai dengan kalender pendidikan yang telah disepakati. Pelaksanaan tugas sesuai dengan deskripsi tugas yang sudah tertera dalam penugasan. Proses pembelajaran menyesuaikan dengan tema kurikulum 2013 diintegrasikan dengan dasar 5 pilar sekolah dan disesuaikan dengan perkembangan usia peserta didik. Pembelajaran untuk peserta didik berkebutuhan khusus digabungkan dengan anak biasa dalam satu kelas, namun terdapat jam tertentu ditarik keluar (pull out) untuk belajar dalam Program Pembelajaran Individual (PPI). Peserta didik berkebutuhan khusus memiliki fasilitator pendamping ABK. Kegiatan di luar pembelajaran dalam kelas dilaksanakan oleh penanggung jawab kegiatan yang sudah ditunjuk dengan membentuk tim pelaksanaan kegiatan. Terdapat lighthouse team yang dibentuk untuk bertanggungjawab terhadap kegiatan penanaman nilai kepemimpinan peserta didik. Sekolah menyediakan program pengembangan diri sebagai penunjang pengembangan potensi peserta didik.

SD Kreativa menyusun peraturan-peraturan yang harus ditaati oleh sumber daya manusia di sekolah. Peraturan disusun untuk dijadikan panduan dalam bertindak dan memberi batasan pada proses pendidikan di SD Kreativa agar tetap di jalur yang benar dalam rangka mencapai tujuan sekolah. Peraturan untuk sumber daya manusia pengelola sekolah seperti manajemen, staf, dan fasilitator diatur dalam peraturan kepegawaian yang ditetapkan oleh bagian manajemen SDM dan umum yayasan. Selain itu, terdapat peraturan yang dilaksanakan dalam satu tahun pembelajaran yang disepakati bersama semua SDM pengelola sekolah pada rapat kerja sekolah. Peraturan yang diterapkan untuk peserta didik dituangkan dalam tata tertib sekolah yang dimuat dalam handbook Sekolah Kreativa. Handbook berisi informasi lengkap mengenai visi, misi, program pembelajaran di Sekolah Kreativa dan peran orang tua dalam proses pembelajaran peserta didik.

Pada tahap pengendalian, Pengendalian dilakukan dengan proses monitoring dan evaluasi terhadap hasil pembelajaran peserta didik dan kinerja fasilitator. Secara rutin, kepala sekolah melakukan pemantauan kegiatan yang berjalan untuk memastikan pelaksanaan kegiatan sesuai dengan rencana yang disusun. Kepala sekolah juga memastikan target tujuan sekolah, pembelajaran peserta didik, dan kinerja fasilitator dapat tercapai. Sama halnya dengan pendapat Chairunnisa (2016: 200) yang menyebutkan bahwa pengendalian merupakan upaya yang dimaksudkan untuk menjaga agar penyelenggaraan kegiatan organisasi dilaksanakan sesuai dengan perencanaan yang telah dibuat dan disusun.

\section{d. Sub Fokus 4: Pengendalian}

Wewenang monitoring dan evaluasi program pendidikan sekolah dilakukan oleh kepala sekolah. Kepala sekolah sebagai supervisor bertanggung jawab untuk memantau, membina, dan memperbaiki proses kegiatan pendidikan di sekolah. Wewenang kepala sekolah tersebut dibantu oleh wakil kepala sekolah untuk melakukan monitoring dan evaluasi fasilitator dan proses pembelajaran. Selain itu, wewenang kepala sekolah juga dibantu oleh fasilitator untuk melakukan monitoring dan evaluasi terhadap proses pembelajaran peserta didik. Yayasan memiliki bagian manajemen penjamin mutu untuk melaksanakan audit proses manajemen mutu di sekolah.

Monitoring dan evaluasi fasilitator serta program pendidikan dilakukan oleh kepala sekolah bersifat rutin secara bulanan, semester, dan tahunan. Evaluasi bulanan dilakukan melalui kegiatan briefing akbar. Evaluasi fasilitator tiap semester menggunakan Key Performance Indicator (KPI). Evaluasi tahunan dilaksanakan melalui rapat kerja sekolah. Kepala sekolah dibantu oleh 4 wakil kepala sekolah untuk melakukan monitoring dan evaluasi terhadap fasilitator dan proses pembelajaran setiap minggu. Wakil kepala sekolah meneruskan hasil evaluasi tersebut kepada kepala sekolah. Pengurus yayasan melakukan monitoring pelaksanaan program pendidikan setiap bulan melalui kegiatan rapat bersama manajemen sekolah. Monitoring dan evaluasi peserta didik dilakukan melalui penilaian sikap yang dilakukan setiap hari, penilaian tengah semester, dan penilaian akhir semester. Mekanisme monitoring dan evaluasi anak berkebutuhan khusus sama dengan anak biasa, namun lebih fleksibel menyesuaikan perkembangan peserta didik.

Mekanisme pelaporan hasil monitoring dan evaluasi program pendidikan SD Kreativa disusun oleh manajemen sekolah, selanjutnya dilaporkan kepada Yayasan Yasmina setiap tahun. Laporan hasil monitoring dan evaluasi juga dilaporkan secara lisan melalui rapat dengan manajemen yayasan setiap bulan. Mekanisme pelaporan hasil monitoring dan evaluasi peserta didik melalui rapor narasi dan rapor semester. Rapor narasi berisi deskripsi perkembangan pembelajaran peserta didik dan hasil nilai ujian tengah semester yang dilaporkan saat pertengahan semester kepada orang tua melalui pengesahan kepala sekolah. Rapor semester berisikan capaian belajar siswa yang selama satu semester pembelajaran dan dilaporkan setiap semester kepada orang tua melalui pengesahan kepala sekolah

Penerapan 5 pilar berdampak kepada tercapainya tujuan sekolah. Dampak penerapan 5 pilar terlihat dari sikap peserta didik yang berakhlak Islami dan juga prestasi yang diperoleh sekolah dan siswa. Penghargaan yang diperoleh sekolah antara lain sekolah adiwiyata, sekolah berbudaya lingkungan, lighthouse school kepemimpinan, sekolah penyelenggaran pendidikan inklusi, dan penghargaan kemanusiaan. Prestasi yang diperoleh siswa antara lain juara tahsin dan tahfid Al-Quran, juara 
kompetisi matematika, dan juara lainnya yang diperoleh dari pengembangan potensi peserta didik. Selain itu, dampak penerapan 5 pilar dapat dilihat dari kebiasaan peserta didik di sekolah dan di rumah. Peserta didik lebih percaya diri, disiplin, bertanggung jawab, aktif dalam belajar dan beribadah. Selain itu, peserta didik lebih peduli terhadap lingkungan sekitarnya. Peserta didik lulusan SD Kreativa melanjutkan ke jenjang pendidikan SMP. Peserta didik mendapatkan ijazah sesuai ketentuan Dinas Pendidikan Kota Bogor yang dapat digunakan untuk melanjutkan SMP negeri maupun swasta. SMP Kreativa memberikan prioritas terhadap lulusan SD Kreativa yang akan melanjutkan pendidikannya, termasuk untuk anak berkebutuhan khusus.

\section{SIMPULAN}

Manajemen sekolah berperan penting untuk pencapaian tujuan sekolah. Manajemen digunakan sebuah organisasi untuk mencapai tujuan. Sekolah menerapkan fungsi manajemen mulai dari proses perencanaan, pengorganisasian, pengarahan, dan pengendalian dengan baik. Sekolah Dasar Kreativa mewujudkan pengembangan akhlak Islami peserta didik dengan menerapkan 5 pilar: Islamic, Green, Leadership, Children Friendly, dan Inclusive sebagai dasar dalam pelaksanaan program pendidikan. Keberhasilan penerapan 5 pilar untuk mencapai tujuan sekolah juga didukung oleh Faktor pendukung pelaksanaan program pendidikan di Sekolah Dasar Kreativa antara lain sumber daya manusia, dukungan orang tua, dan dukungan Yayasan. Selain itu, ada faktor penghambat pelaksanaan program pendidikan di SD Kreativa ini karena kondisi yang tidak bisa diprediksi. Pandemi covid 19 yang sedang dialami mengharuskan SD Kreativa yang sebelumnya mengandalkan interaksi dan pengalaman langsung peserta didik berubah menjadi pembelajaran daring. Hal ini menjadi pekerjaan yang harus diselesaikan oleh SD Kreativa agar pembelajaran bisa berjalan lancar. Penerapan 5 pilar SD Kreativa berdampak pada tercapainya tujuan sekolah. Hasil dari penerapan 5 pilar yang konsisten dilakukan sekolah dapat dilihat dari prestasi yang diraih oleh sekolah dan peserta didik. Selain itu, dampak pembelajaran SD Kreativa terlihat pada karakter dan kebiasaan peserta didik di sekolah ataupun di rumah. Peserta didik lebih percaya diri, disiplin, bertanggung jawab, aktif dalam belajar dan beribadah. Selain itu, peserta didik lebih peduli terhadap lingkungan sekitarnya

\section{REFERENSI}

Arabiun, A.G. (2014). The Importance of Management for Growing and Developing Agribusiness SMEs: Designing a Conceptual Framework. International Review. 1. (2): 25-44.

Arif, Saiful Nur dan Zulkarnain, Iskandar. (2008). Dasar-Dasar Manajemen dalam Teknologi Informasi. Jurnal Saintikom. 5(2): 236-247.

Cabral, C. (2019). Green Competencies: Construct development and measurement validation. Jurnal of Cleaner Production. 235:887-900.

Chairunnisa, Connie. (2016). Manajemen Pendidikan dalam Multi Perspektif. Depok: PT. Rajagrafindo Persada.

Covey, S.R. (2008). The Leader in Me. Terjemahan Fairano Ilyas. Jakarta: Gramedia.

Hasan, Md. Mahmudul. (2016). Islamic literature: definition, nature, and scope. IIUC Studies. 13: 43-52.

Mahmud, Akilah. (2019). Ciri Dan Keistimewaan Akhlak Dalam Islam. Sulesana. 13. (1): 29-40.

Nurochim. (2016). Administrasi Pendidikan. Bekasi: Gramata Publishing.

Robinson, D. (2017). Effective Inclusive Teacher Education For Special Educational Needs and Disabilities: Some More Thoughts On The Way Forward. Teaching and Teacher Education. (61):164-178.

Siswanto, B. (2011). Pengantar Manajemen. Jakarta: Paragonatama Jaya.

Sutikno, Sobry. (2012). Manajemen Pendidikan Langkah Praktis Mewujudkan Lembaga Pendidikan Yang Unggul. Lombok: Holistica. 